\title{
Patient-Centered Drug Approval: The Role of Patient Advocacy in the Drug Approval Process
}

\author{
T. Joseph Mattingly II, PharmD, MBA, and Linda Simoni-Wastila, BSPharm, MSPH, PhD
}

\begin{abstract}
SUMMARY
Recent approval of eteplirsen for Duchenne muscular dystrophy (DMD), a rare disease with few treatment alternatives, has reignited the debate over the U.S. drug approval process. The evolution of legal and regulatory restrictions to the marketing and sale of pharmaceuticals has spanned more than a century, and throughout this history, patient advocacy has played a significant role. Scientific evidence from clinical trials serves as the foundation for drug approval, but the patient voice has become increasingly influential. Although the gold standard for establishing safety and efficacy through randomized controlled trials has been in place for more than $\mathbf{5 0}$ years, it poses several limitations for rare disorders where patient recruitment for traditional clinical trials is a major barrier. Organized efforts by patient advocacy groups to help patients with rare diseases access investigational therapy have had a legislative and regulatory effect.

After approval by the FDA, patient access to therapy may still be limited by cost. A managed care organization (MCO) with the fiduciary responsibility of managing the health of a population must weigh coverage decisions for costly therapies with questionable effectiveness against alternatives within the constraint of a finite budget. Even when the FDA deems a drug safe and effective, an MCO may determine that the drug should only be made available at a tier level where out-of-pocket costs are still too high for many patients. This limitation of availability may be due to cost, other treatment alternatives, or outcomes from existing clinical evidence. However, if the MCO makes a costly new treatment for a rare disease readily available, it may temporarily satisfy a small contingency at the cost of all of its members. This article examines the risks and benefits of patientcentered drug approval and the potential economic effect of patientcentered drug approval on population health.
\end{abstract}

J Manag Care Spec Pharm. 2017;23(10):1078-82

Copyright $\odot 2017$, Academy of Managed Care Pharmacy. All rights reserved.

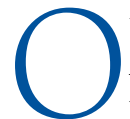
n September 19, 2016, the U.S. Food and Drug Administration (FDA) approved the drug eteplirsen, which is indicated to treat the rare disease known as Duchenne muscular dystrophy (DMD). ${ }^{1}$ Approval of eteplirsen was met with controversy as the debate between high-ranking FDA officials over whether to approve the drug became public. ${ }^{2}$ Earlier, in April 2016, an advisory panel had voted 7 to 3 that the evidence provided by the pharmaceutical manufacturer did not meet FDA requirements for approval, even though a wellorganized patient advocacy group brought hundreds of patients and family members to the meeting in Hyattsville, Maryland, to plead the case for approval. ${ }^{3}$ In July 2016, the director of FDA's Center of Drug Evaluation and Research, Dr. Janet Woodcock, announced a decision to approve eteplirsen under the accelerated approval pathway, which was then appealed. ${ }^{4}$
Dr. Ellis Unger of the FDA's Office of Drug Evaluation under Dr. Woodcock stated the following in his appeal of the decision to approve eteplirsen: "Patient-focused drug development is about listening to patient perspectives about what matters to them; it is not about basing drug approvals on anecdotal testimony that is not corroborated by data."

When the decision to approve was upheld in 2016, the FDA released the internal dispute documents, which showed the challenges faced in the drug approval process. In addition to difficult science and trial evaluations, the FDA cited enormous political pressure in the case of DMD in its summary report, citing the example that then FDA Commissioner Dr. Robert Califf received 2,792 emails from patient advocates alone urging eteplirsen's approval. ${ }^{4,5}$ The approval of eteplirsen raised speculation regarding the future of drug approval to focus more on patients' needs for new pharmaceuticals. This speculation increased after the 2016 U.S. presidential election, since President Donald Trump's health care platform emphasized FDA reform. ${ }^{6}$

The potential effect of FDA reform intended to speed up the drug approval process requires analysis of potential winners and losers. Pharmaceutical manufacturers stand to gain from faster approval by simultaneously cutting research costs and capturing revenue over a longer proportion of their patent term. By lowering the regulatory barrier to enter a market, competition also may improve in areas where only 1 or 2 companies dominate. Patients who suffer from diseases where few therapeutic options exist also could benefit from FDA reform, since new treatments could be made available sooner. However, determining whether exposure to a drug approved through a process with a lower bar for safety and efficacy is a net benefit or cost would be done after approval. So the real winners and losers may not be known until it is too late. In addition to determining costs and benefits for each clinical area, understanding the effect on patients and on the entire system may pose different challenges. If patient and payer resources shift to purchase a new therapy, it takes away available resources for existing treatments that may be just as effective.

This article explores the risks and benefits of patient-centered drug approval on population health through the contextual lens of historical events in the past half century that have influenced the regulation of pharmaceuticals in the United States, focusing on legislation, patient advocacy, and potential unintended consequences. 


\section{Legislation and Expedited Drug Approval}

In December 1959, the Senate Subcommittee on Antitrust and Monopoly held a series of hearings with several witnesses, including physicians, drug manufacturers, pharmacists, and other industry experts, to examine the pricing practices of pharmaceuticals. ${ }^{7,8}$ Led by Senator Estes Kefauver, the subcommittee raised serious concerns about the potential price gouging of prescription drugs with unsubstantiated claims of efficacy. ${ }^{9}$ Kefauver drafted a bill that enabled the FDA to review claims of efficacy before approval, monitor advertising, ensure the use of readable generic names, allow compulsory licensing for new drugs after 3 years, and eliminate "me-too drugs" by providing patents only if the new drug produced a significantly greater therapeutic effect. ${ }^{9}$ With major opposition to many of the provisions and a need to act following a highly visible thalidomide tragedy in Europe, what resulted was a bill that allowed the FDA to require proof of efficacy from clinical trials and has been dubbed the Kefauver-Harris Amendments to the Food, Drug, and Cosmetic Act. ${ }^{9}$ Often these amendments are discussed in the context of safety and efficacy requirements, but we tend to forget about the antimonopoly underpinning established by Senator Kefauver.

The 1962 Kefauver-Harris Amendments undoubtedly transformed the landscape for drug approval in the United States. While often attributed with praise for advancing patient safety, the additional burden of proof of efficacy has created the potential for "drug lag" in the United States, since the FDA approval process is considered slow compared with other countries. ${ }^{10}$ This conservative and cumbersome approval process may be viewed negatively from the perspective of a patient waiting for a new treatment, especially with regard to diseases such as DMD, where few alternatives exist. ${ }^{11}$

Twenty-one years after the passage of the Kefauver-Harris Amendments, the Orphan Drug Act (ODA) of 1983 was enacted to address the need for therapies for rare diseases. ${ }^{12}$ The ODA provides several incentives to manufacturers and is considered a success in terms of increasing the number of treatments approved for rare conditions by the FDA. ${ }^{13}$ As one might expect, recruiting patients with a particular rare disease for a clinical trial poses a challenge for companies seeking to prove the efficacy of a new molecule. Compared with nonorphan drugs, clinical trials used to gain FDA approval are typically much smaller for orphan drug applications. ${ }^{12,14}$

Although the requirement of safety and efficacy evidence from controlled trials was not changed by the 1983 ODA, the FDA has made efforts to allow flexibility in assessment of the evidence for diseases with unmet needs..$^{15}$ In addition to the informal adjustments in the standard approval process, the FDA has also created pathways of expanding access to drugs before approval, as well as expedited approval processes for life-saving or breakthrough therapies. ${ }^{16}$ Eteplirsen was approved on this accelerated pathway based on surrogate endpoints of protein levels that may potentially have a clinical benefit, although those clinical benefits were never established in the trials submitted to the FDA. ${ }^{1}$

The recent signing of the 21st Century Cures Act into law marks another pivotal point in the history of drug approval, with the inclusion of mechanisms aimed to "accelerate the discovery, development, and delivery" of new drugs and devices. ${ }^{17,18}$ Critics of the law cite the encouragement of using biomarker or surrogate endpoints in clinical trials to determine the efficacy of drugs and devices, even though the FDA already uses biomarkers in roughly half of new drug approvals. ${ }^{19}$ The comprehensive law also includes a wide range of provisions to increase funding in areas such as cancer, opioid addiction, and mental health, and includes an entire section devoted to Patient-Focused Drug Development, an FDA initiative. ${ }^{17}$

Another interesting component of the passage of the Cures Act is the overwhelming consensus by Republicans and Democrats and the ability to finalize the law in the last weeks of President Barack Obama's administration. ${ }^{18}$ Given the bipartisan support for the legislation, the concerted effort to accelerate innovation to treat disease, despite the warnings of some experts concerned about safety and efficacy, demonstrated how the public felt about finding a cure. The concern for inappropriate drug approval has not gone away; however, this law may signal that patients and caregivers are willing to accept the risk for even the smallest chance of improvement in the current state of their disease.

\section{Advocating for Patient Rights}

The HIV/AIDS epidemic of the 1980s unleashed a wave of attacks on the FDA for the slow development of new therapies approved to treat the disease. ${ }^{20}$ A process developed to protect patients from the dangers of investigational molecules was now the primary target for an organized patient advocacy movement that wanted access to drugs before the traditional approval pathway. ${ }^{20}$ These advocacy efforts helped influence the FDA to permit the sale of investigational drugs through a "compassionate use" mechanism and helped lead the way to some of the expanded access pathways previously mentioned.

In 2001, in the wake of 21-year-old Abigail Burroughs's battle with cancer, the Abigail Alliance was formed, and a lawsuit was filed against the FDA that argued that patients have a constitutional right to access experimental drugs. ${ }^{21}$ While the case ultimately failed when a federal court of appeals decided in favor of the FDA, and the Supreme Court declined to review, patient advocates have continued to fight at the state level with "right-to-try" laws that allow manufacturers to provide medications to the terminally ill before FDA approval. ${ }^{22}$ The safety and efficacy requirements for drug approval may work as a general framework to regulate the pharmaceutical discovery process for most patients, but from the perspective of a dying patient, this framework may be insufficient. 
In the case of $\mathrm{DMD}$, there have been very strong patient advocacy efforts and visually powerful campaigns to help increase awareness of the disease and its effect on the young boys that suffer from it. For example, Christine and Stephen McSherry started the Jett Foundation after Christine's son Jett was diagnosed with DMD and has since raised over \$13 million for research. ${ }^{23}$ McSherry was one of the mothers who testified to the FDA and considers the approval of eteplirsen a victory for rare diseases and also for "patient input and perseverance." 23 In addition to testimony, the FDA adopted a patient advocacyled guidance to help the industry better understand muscular dystrophy and design better trials to study the disease. ${ }^{24}$

\section{Exploiting Hope and Unintended Consequences}

Approval of a new drug based on limited or questionable efficacy data has the potential to revert the market of pharmaceuticals to a pre-1962 era, in which manufacturers benefit from the sale of "snake oil" drugs that may offer hope but no positive outcome. For the terminally ill patient, added hope may or may not be detrimental clinically but could have catastrophic financial consequences. A dying patient willing to pay any amount in the interest of self-preservation provides perfect market conditions for the price gouging Senator Kefauver wanted to end with his amendments., ${ }^{7,9}$

Another challenge revolves around the marketing language used by a manufacturer after FDA approval..$^{16}$ If a drug is approved on weaker evidence, there may be a need to enforce stricter rules around the promotion of the drug so as not to imply or overstate the efficacy in direct or indirect advertisements. With recent court decisions favoring the right of drug manufacturers to free speech in terms of drug promotion, it may be difficult for the FDA to adequately regulate without statutory considerations from Congress. ${ }^{16}$

Following FDA approval, inclusion of a new drug on a managed care formulary not only has implications for the intended patients but also could increase the overall budget for the health plan. Additional use for brand name pharmaceuticals may drive insurance premiums up for the entire health plan, depending on the cost of the drug and total number of patients treated within a particular plan. From a population health perspective, high-cost drugs with questionable efficacy may inappropriately allocate resources. The price tag for treatment with eteplirsen is estimated to cost $\$ 300,000$ annually, and its weak clinical evidence has payers split on whether to cover the drug. ${ }^{25-27}$ In cases where health plans use patient copayment or cost-sharing mechanisms to influence use, patient assistance programs are being established for DMD to help circumvent these managed care levers. ${ }^{28}$

If the bar for drug approval based on efficacy is adjusted based on patient-centered needs, will manufacturers be motivated to provide additional data after approval? While the FDA could make additional research a requirement of a conditional approval, market availability could negatively effect clinical trial recruitment, since patients may be less willing to take the chance that they might end up in the placebo-control group. In addition to the approved drug, lowered expectations of efficacy results could effect all pipeline drugs in similar disease states. Drug manufacturers may see this as an opportunity to reduce phase 3 clinical trial expenditures or shift these expenditures to patients and payers by seeking approval first with the contingencies from the FDA to continue studying in phase 4.

From a patient-centered standpoint, the decision to pay for a therapy may be more straightforward compared with the population or society perspective. It would be difficult to tell a patient suffering from a debilitating disease that his or her treatment is not covered, especially when the drug has been approved by the FDA. This may be a rationale to support a different designation or "conditional approval" label that allows a distinction between a drug with enough safety and efficacy data to support full approval. However, treatment coverage decisions are not made in a vacuum, since the decision to commit resources in one area may take away available resources for another. Strong evidence from clinical trials supporting safety and efficacy claims following FDA approval makes the decision less controversial, but when the scientific community and regulating agencies are publicly disputing the clinical evidence, the decision becomes much more complicated.

\section{Finding a Balance}

Regulatory changes that helped speed up the drug approval process for eteplirsen and other products may put some patients at an additional risk; however, allowing patients the option of accepting risk may be a fair compromise. Patients could be given the option to enter a contractual agreement with pharmaceutical manufacturers, waiving some or all liability for these risks, but the concept of contractual liability has its challenges. ${ }^{29-31}$ Such a compromise still would not address challenges in patient or caregiver decision making, where it may not be a reasonable assumption that average consumers will fully understand potential additional risks. The term "informed consent" is often used in research to attempt to demonstrate that study subjects are aware of the risks involved with participation. For patients deciding whether to take eteplirsen, the lack of other options may create a desperate situation in which they may be willing to purchase anything, even if the evidence reflects little more than a placebo. From the perspective of pharmaceutical manufacturers, a rare disease with limited treatment options may favor a pricing strategy in the tens or hundreds of thousands of dollars to be profitable over a therapeutic area with a larger consumer base.

The "compassionate use" or expanded access program provides a way for patients and physicians to work with pharmaceutical manufacturers to access investigational drugs before approval. ${ }^{32}$ Several challenges have limited the use of 
this particular pathway, including administrative burdens, physician and patient awareness, and the potential to reduce enrollment in ongoing clinical trials needed to obtain full FDA approval. ${ }^{22}$ One parent with 2 young boys with DMD experienced the complexities of the expanded access program as 1 of her children, who did not qualify for a clinical trial, was denied compassionate use because of limited drug supply. ${ }^{33}$ While the program provides a mechanism for companies to work with patients and providers, only a small fraction of active clinical trials are engaging patients through this compassionate use scenario. ${ }^{22}$ Perhaps a new designation for conditional approval by the FDA could make the product available on the market where the manufacturer could earn revenue to support production but establish rules to limit the exploitation previously discussed. With conditional approval, further limitations on pricing or marketing to consumers could be included to address these concerns.

Is there a solution to help increase access without potentially harming patients? When a new drug is approved with limited clinical trial data, the potential value of the drug is still unclear. In addition, we need to consider patient and provider expectations for therapies with limited clinical efficacy or safety evidence. Improving the communication of potential risks and benefits could help manage expectations for patients vulnerable to exploitation. It may be worth exploring options where prices for products such as eteplirsen are restricted or fixed at a level that supports continued development until evidence demonstrates an unrestricted approval. However, it is worth noting that many health services are offered with no prospective regulatory expectation of safety or efficacy, which may be more of a criticism of the lack of oversight in other areas rather than a suggestion to lessen the burden of proof in the pharmaceutical industry. If the FDA had the authority to regulate every type of medical intervention with the same scrutiny as a pharmaceutical product, the barrier to entry would likely prevent many common practices currently used in our health care system.

\section{Authors}

T. JOSEPH MATTINGLY II, PharmD, MBA, Department of Pharmacy Practice and Science, and LINDA SIMONI-WASTILA, BSPharm, MSPH, PhD, Department of Pharmaceutical Health Services Research, University of Maryland School of Pharmacy, Baltimore.

AUTHOR CORRESPONDENCE: T. Joseph Mattingly II, PharmD, MBA, University of Maryland School of Pharmacy, 20 N. Pine St., N415, Baltimore, MD 21201. Tel.: 410.706.8068;

E-mail: jmattingly@rx.umaryland.edu.

\section{DISCLOSURES}

There is no funding to disclose. Mattingly reports advisory board fees from Summit Therapeutics and an educational grant from ALK, outside of this article. Simoni-Wastila has nothing to disclose.

Mattingly took the lead in conceptualizing this Viewpoint article and writing the manuscript, along with Simoni-Wastila. Both authors contributed equally to manucript revision.

\section{REFERENCES}

1. U.S. Food and Drug Administration. FDA grants accelerated approval to first drug for Duchenne muscular dystrophy. FDA news release. September 19, 2016. Available at: https://www.fda.gov/NewsEvents/Newsroom/ PressAnnouncements/ucm521263.htm. Accessed August 18, 2017.

2. Silverman E. FDA approves Sarepta's controversial drug for Duchenne muscular dystrophy. STAT. September 19, 2016. Available at: https://www. statnews.com/pharmalot/2016/09/19/sarepta-wins-dmd-drug-approval/. Accessed August 18, 2017.

3. Pollack A. Advisors to FDA vote against Duchenne muscular dystrophy drug. The New York Times. April 25, 2016. Available at: https://www.nytimes. com/2016/04/26/business/muscular-dystrophy-drug-fda-sarepta-eteplirsen. html?_r=0. Accessed August 18, 2017.

4. Center for Drug Evaluation and Research. Memo re: Scienfic dispute regarding accelerated approval of Serapta Theraputics' eteplirsen. Summary review. Application no. 2064880rigls000. September 16, 2016. Available at: https://www.accessdata.fda.gov/drugsatfda_docs/nda/2016/206488_summary\%20review_Redacted.pdf. Accessed August 18, 2017.

5. Garde D. Did the FDA set "a dangerous precedent" with its latest drug approval? STAT. September 19, 2016. Available at: https://www.statnews.com/ pharmalot/2016/09/19/fda-sarepta-precedent/. Accessed August 18, 2017.

6. Johnson CY. Trump just dropped a big hint to the pharmaceutical industry. The Washington Post. November 14, 2016. Available at: https://www. washingtonpost.com/news/wonk/wp/2016/11/14/trump-just-dropped-a-bighint-to-the-pharmaceutical-industry/. Accessed August 18, 2017.

7. Kefauver E, Till I. In a Few Hands: Monopoly Power in America. New York: Pantheon Books; 1965.

8. Scroop D. A faded passion? Estes Kefauver and the Senate Subcommittee on Antitrust and Monopoly. Bus Econ Hist On-Line. 2007;5:1-17. Available at: http:// www.thebhc.org/sites/default/files/scroop.pdf. Accessed August 23, 2017.

9. Greene JA, Podolsky SH. Reform, regulation, and pharmaceuticals-the Kefauver-Harris amendments at 50. N Engl J Med. 2012;367(16):1481-83.

10. Abraham J, Davis C. A comparative analysis of drug safety withdrawals in the UK and the US (1971-1992): implications for current regulatory thinking and policy. Soc Sci Med. 2005;61(5):881-92.

11. Carpenter DP. The political economy of FDA drug review: processing, politics, and lessons for policy. Health Aff (Millwood). 2004;23(1):52-63.

12. Orfali M, Feldman L, Bhattacharjee V, et al. Raising orphans: how clinical development programs of drugs for rare and common diseases are different. Clin Pharmacol Ther. 2012;92(2):262-64.

13. Ulrich LC. Efforts to develop orphan drugs: the FDA experience. Pharm Policy Law. 2010;12:53-55.

14. Kesselheim AS, Myers JA, Avorn J. Characteristics of clinical trials to support approval of orphan vs nonorphan drugs for cancer. JAMA. 2011;305(22):2320-26.

15. Frank J. Sasinowski. Quantum of effectiveness evidence in FDA's approval of orphan drugs. Drug Inf J. 2012;46(2):238-63.

16. Kesselheim AS, Tan YT, Darrow JJ, Avorn J. Existing FDA pathways have potential to ensure early access to, and appropriate use of, specialty drugs. Health Aff (Millwood). 2014;33(10):1770-78. 
17. 21 st Century Cures Act. HR 6. 114th Congress (2015-2016). Available at: https://www.congress.gov/bill/114th-congress/house-bill/6. Accessed August 18, 2017.

18. Eilperin J, Johnson CY. Obama, paying tribute to Biden and bipartisanship, signs 21 st Century Cures Act Tuesday. The Washington Post. December 13, 2016. Available at: https://www.washingtonpost.com/news/powerpost/ wp/2016/12/13/obama-p. Accessed August 18, 2017.

19. Avorn J, Kesselheim AS. The 21st Century Cures Act-will it take us back in time? N Engl J Med. 2015;372(26):2473-75.

20. Edgar H, Rothman DJ. New rules for new drugs: the challenge of AIDS to the regulatory process. Milbank Q. 1990;68(Suppl 1):111-42.

21. Okie S. Access before approval - a right to take experimental drugs? N Engl J Med. 2006;355(5):437-40.

22. Darrow JJ, Sarpatwari A, Avorn J, Kesselheim AS. Practical, legal, and ethical issues in expanded access to investigational drugs. $N$ Engl J Med. 2015;372(3):279-86

23. Kandarian PE. Pembroke mom fights to help find cure for Duchenne. Boston Globe. November 18, 2016. Available at: https://www.bostonglobe. com/metro/regionals/south/2016/11/18/pembroke-mom-fights-help-findcure-for-duchenne/3YJg0rcnKQoSTcbzQirthN/story.html. Accessed August 18, 2017.

24. Anderson M, Schneeman K. How patient groups have begun to influence the value and coverage debate. Health Affairs Blog. June 10, 2016. Available at: http://healthaffairs.org/blog/2016/06/10/how-patient-groups-have-begunto-influence-the-value-and-coverage-debate/. Accessed August 18, 2017.

25. Pagliarulo N. Humana to cover Sarepta's DMD drug with caveats. BioPharmaDIVE. October 26, 2016. Available at: http://www.biopharmadive.com/news/humana-to-cover-sareptas-dmd-drug-with-caveats/429085/ Accessed August 18, 2017.
26. Cox T. Aetna still undecided on coverage for Sarepta's highly debated muscular dystrophy treatment. Benzinga. November 21, 2016. Available at: https://www.benzinga.com/general/biotech/16/11/8725155/aetna-stillundecided-on-coverage-for-sareptas-highly-debated-muscular. Accessed August 18, 2017.

27. Sagonowsky E. "Big 3" insurer Anthem refuses to cover Sarepta's controversial DMD med Exondys 51. FiercePharma. October 10, 2016. Available at: http://www.fiercepharma.com/pharma/anthem-declines-coverage-sarepta-scontroversial-dmd-med-exondys-51. Accessed August 18, 2017.

28. The Assistance Fund. The assistance fund now providing financial assistance to patients with duchenne muscular dystrophy. Business Wire. October 27, 2016. Available at: http://www.businesswire.com/news/ home/20161027006112/en/Assistance-Fund-Providing-Financial-AssistancePatients-Duchenne. Accessed August 18, 2017.

29. Thaler RH, Sunstein CR. Nudge: Improving Decisions About Health, Wealth, and Happiness. New York: Penguin Group; 2008.

30. Epstein RA. Medical malpractice, imperfect information, and the contractual foundation for medical services. Law Contemp Probl. 1986;49(2):201-12.

31. Arlen J. Contracting over liability: medical malpractice and the cost of choice. Univ PA Law Rev. 2010;158(4):101-66. Available at: https://www. researchgate.net/publication/30505035_Contracting_Over_Liability_ Medical_Malpractice_and_the_Cost_of_Choice. Accessed August 18, 2017.

32. U.S. Food and Drug Administration. Expanded access: information for patients. 2016. Available at: https://www.fda.gov/ForPatients/Other/ ExpandedAccess/ucm20041768.htm. Accessed August 18, 2017.

33. Westphal SP. Sick kids, desperate parents, and the battle for experimental drugs: the complex world of compassionate use drugs and who gets access to them. Boston Globe. July 15, 2015. Available at: https://www.bostonglobe.com/magazine/2015/07/15/sick-kids-desperate-parents-and-battlefor-experimental-drugs/Hle3CTwriFfTXoOvQ7TbZP/story.html. Accessed August 18, 2017. 